\title{
Bilateral Stress Fracture of the Fibulae and Periostitis of the Tibiae
}

\author{
Hiroyuki Tsuchie Kyoji Okada Hiroyuki Nagasawa Shuichi Chida \\ Yoichi Shimada \\ Department of Orthopedic Surgery, Akita University Graduate School of Medicine, Akita, Japan
}

\section{Key Words}

Stress fracture, bilateral · Fibula

\begin{abstract}
Objective: This study describes a unique case of bilateral stress fractures of the fibulae and provides a literature review. Clinical Presentation and Intervention: A 16-year-old female badminton player presented with pain around the bilateral distal lateral legs. She had mild bilateral varus deformity at the knee joint, and the bilateral ankles showed valgus deformity in standing posture. Radiographs and computed tomography showed periosteal reactions on the bilateral distal fibulae. Technetium-99m bone scintigraphy demonstrated increased uptake in the bilateral distal fibulae and the bilateral middle third of the tibiae. A diagnosis of bilateral distal fibular stress fractures was made. She was advised to stop playing badminton until the symptoms disappeared. Conclusion: Varus deformity of the knee and valgus deformity of the ankle may have influenced the mechanism underlying bilateral symmetric stress fractures.
\end{abstract}

Copyright $\odot 2010$ S. Karger AG, Basel

\section{Introduction}

Stress fractures generally occur as a result of repetitive accumulation of stresses, and they often occur in athletes [1]. Common sites of the condition are the bones of the lower extremities, but bilateral cases are relatively rare. We describe a unique case of bilateral stress fractures of the fibulae and bilateral periostitis of the tibiae.

\section{Clinical Presentation and Intervention}

A 16-year-old female badminton player presented at our outpatient clinic in October 2008 with pain around the bilateral distal lateral legs that had been present for approximately 4 weeks. Her past and family histories were not contributory and there was no history of trauma. The pain was insidious at onset and gradually increased. The pain became more intense while running and playing badminton. Mild pain was observed during her usual daily activities, but not observed at rest. The pain in the right leg was more intense than in the left. She had been practicing badminton $3 \mathrm{~h}$ a day, 6 times a week for 5 months. Physical examinations demonstrated tenderness at the bilateral distal part of the fibulae and the bilateral anteriomedial site of the mid-tibiae. There was no swelling, deformity or color change. She had mild bilateral varus deformity at the knee joint, and the intercondylar distance of her knees was 2.5 finger widths. In addition, the bilateral ankles showed valgus deformity in standing posture. Radiographs showed periosteal reactions on the bilateral distal fibulae, but there was no change in the tibiae (fig. 1). The right and left femoral-tibial angles were both $180^{\circ}$, and the Mikulicz line, which is the straight line from the center of the femoral head to the center of the ankle joint, ran inside of the center of the knee joint (fig. 2). Thus, there was mild angular deformity of the lower legs. Technetium-99m methylene diphosphonate bone scintigraphy demonstrated an increased uptake in the bilateral distal fibulae and middle tibiae (fig. 3). Computed tomography demonstrated periosteal reactions on the bilateral distal fibulae; the tibiae were normal. Thus, a diagnosis of bilateral distal fibular stress fractures

\section{KARGER}

Fax +4161306 1234

E-Mail karger@karger.ch

www.karger.com
(C) 2010 S. Karger AG, Basel

$1011-7571 / 10 / 0196-0490 \$ 26.00 / 0$

Accessible online at:

www.karger.com/mpp
Hiroyuki Tsuchie

Department of Orthopedic Surgery

Akita University Graduate School of Medicine

1-1-1 Hondo, Akita 0108543 (Japan)

Tel. +81 18884 6148, Fax +81 18836 2617, E-Mail tsuchie@ doc.med.akita-u.ac.jp 

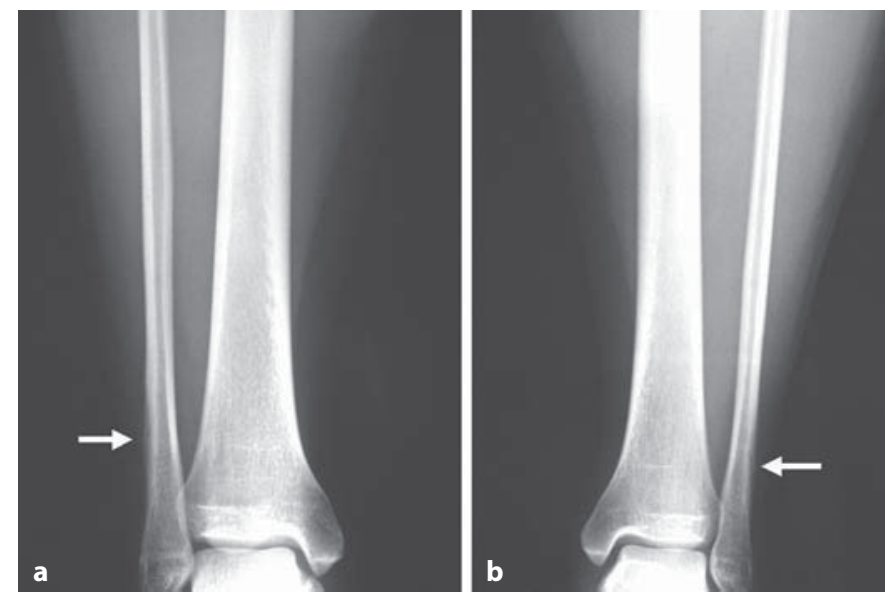

Fig. 1. Anteroposterior radiographs of right (a) and left (b) legs. Radiographs showed fine periosteal reactions in the bilateral distal fibulae (arrows).

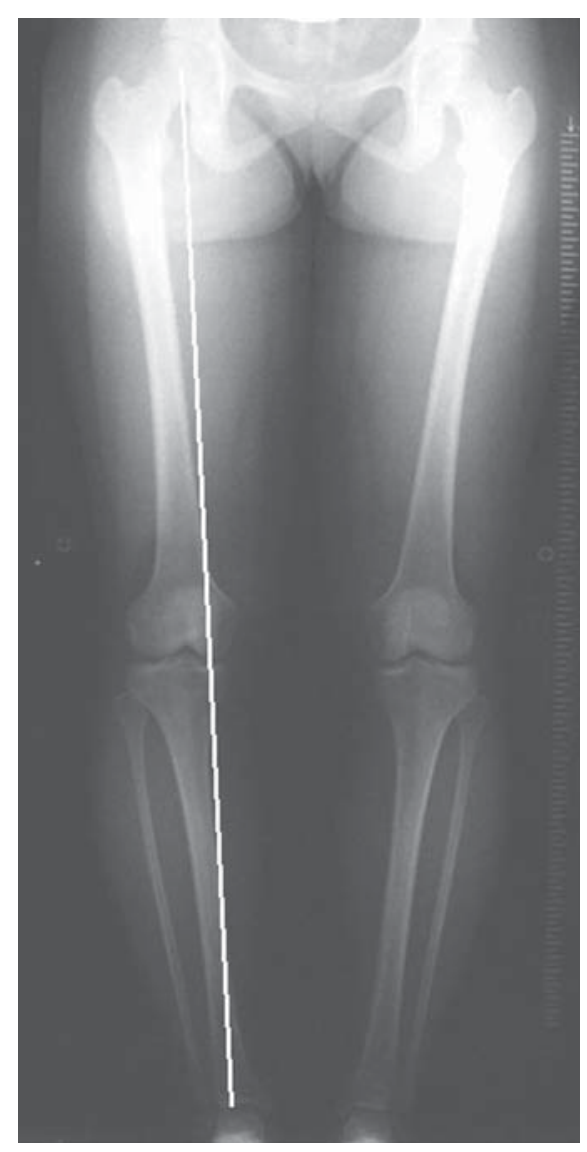

Fig. 2. Anteroposterior radiograph of bilateral lower extremities. Right and left femoral-tibial angles were both $180^{\circ}$, and the Mikulicz line ran inside of the center of the knee joint (white line).

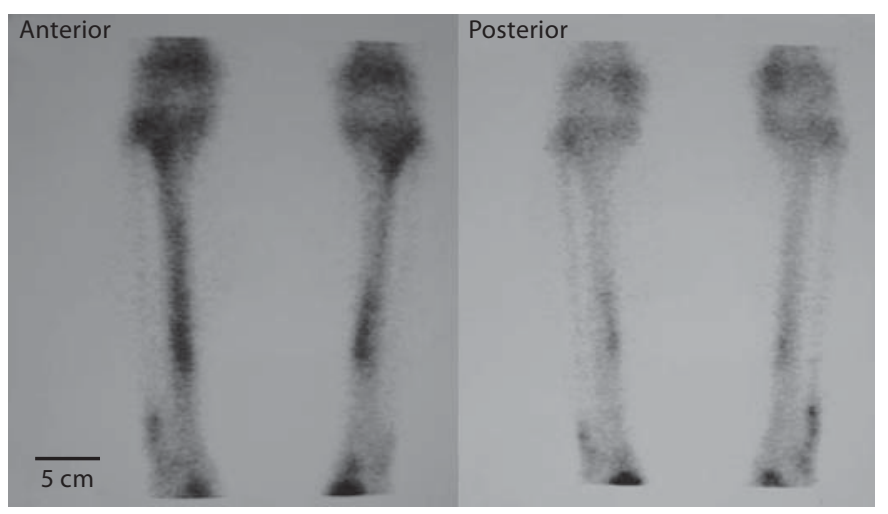

Fig. 3. Technetium-99m methylene diphosphonate bone scintigraphy demonstrated an increased uptake in the bilateral distal fibulae and mid-anterior tibiae.

was made. We recommended that she avoid activity including badminton. Immobilization was not applied.

Pain began to decrease 1 week after the initial visit and almost disappeared 4 weeks later. Radiographs showed consolidation of periosteal reactions in the bilateral distal fibulae. There was no periosteal reaction in the tibiae, and bilateral periostitis (shin splint) was estimated. She began to participate in badminton gradually starting 8 weeks after the initial examination, and there was no pain at the most recent follow-up 4 months after the initial examination.

\section{Discussion}

Stress fractures of the lower extremities generally occur as a result of repetitive accumulation of stress. They are often seen in athletes and military recruits, and usually occur in the lower extremities. In a study of 320 athletes, the most frequent site was the tibia (49.1\%), followed in decreasing order of frequency by the tarsals (25.3\%), metatarsals $(8.8 \%)$, femur $(7.2 \%)$, fibula (6.6\%), pelvis (1.6\%) and sesamoids (0.9\%) [1]. However, reports of bilateral stress fractures have been relatively rare. Matheson et al. [1] suggested that bilateral stress fractures occur in $16.6 \%$ of cases based on an analysis of all stress fracture sites. Although the frequency of bilateral fibular stress fractures has not been precisely reported, it is thought to be quite rare.

Only 7 cases of bilateral fibular stress fractures, which were not insufficiency fractures occurring in abnormal bones with decreased mineralization, have been reported in the literature, and they had histories of sports training (table 1) [2-8]. In general, stress fracture of the fibula is classified according to the level of occurrence: proximal, 
Table 1. Reported cases of bilateral fibular stress fractures

\begin{tabular}{lllll}
\hline Reference & Age, years & Gender & Fibular region & Sporting activity \\
\hline Richmond and Shafar [2], 1955 & 45 & female & more distal & jogging, sewing \\
Synnot and Barry [3], 1984 & 29 & female & more distal & jogging \\
Yasuda et al. [4], 1992 & 15 & male & proximal & fugby \\
Blivin et al. [5], 1999 & 20 & male & middle & tootball \\
Lehman et al. [6], 2002 & 16 & female & proximal & soccer \\
Peiro et al. [7], 2003 & 17 & female & proximal & basketball \\
Roth et al. [8], 2008 & 14 & female & distal and middle & badminton \\
Current case & 16 & female & distal & \\
\hline
\end{tabular}

middle and distal $[3,5,6]$. The lesions of the current patient were distal, most probably due to running activity at the badminton club. The relationship between the region of stress fracture and sport activities is well known; running may cause distal stress fracture and jumping activity the proximal stress fracture [9].

Intense activity such as running may cause unilateral stress fracture of the fibula in a healthy person. However, in the current case, stress fractures occurred symmetrically in the bilateral distal fibulae. In addition, symmetric stress reactions were observed in the bilateral mid-tibiae on bone scintigraphy. To explain the mechanism underlying this bilateral symmetric condition, other intrinsic and bilateral risk factors should be considered. The only detectable abnormality in the current case was varus deformity of the knee and valgus deformity of the ankle in the standing position. Sawant et al. [10] speculated that varus deformity of the knee would produce abnormal stress in both tibiae due to deviation of the mechanical axis. A combination of this abnormal axis and repetitive intense activities might produce stress reaction in the bi- lateral mid-tibiae and bilateral distal fibulae, since the fibula carries between 6.4 and $16.7 \%$ of the load applied to the lower extremity in weight bearing [11]. On biomechanical studies of the fibula, the fibular load is decreased in dorsiflexion or eversion positions and increased in plantar flexion or inversion positions [12]. If the ankles of the current case showed varus deformity, these loads on the fibulae may have increased. However, valgus deformity to compensate for the knee malalignment did not support our speculation. Causes of stress fractures in the bilateral fibulae should be further investigated.

\section{Conclusion}

This reported case showed an athlete with bilateral symmetric stress fracture most probably due to varus deformity of the knee and the ankle. A combination of abnormal axis and repetitive intense activities may produce stress reaction in the bilateral mid-tibiae and bilateral distal fibulae.

\section{References}

1 Matheson GO, Clement DB, McKenzie DC, Taunton JE, Lloyd-Smith DR, Maclntyre JG: Stress fractures in athletes. A study of 320 cases. Am J Sports Med 1987;15:46-58.

2 Richmond DA, Shafar J: A case of bilateral fatigue fractures of the fibula. Br Med J 1955; 1:264-265.

-3 Synnott JL, Barry OC: Bilateral stress fracture of the fused lower fibular epiphysis. Ir J Med Sci 1984;153:252-254.

4 Yasuda T, Miyazaki K, Tada K, Matsuda Y, Murakami H: Stress fracture of the right distal femur following bilateral fractures of the proximal fibulas. A case report. Am J Sports Med 1992;20:771-774.
Blivin SJ, Martire JR, McFarland EG: Bilateral midfibular stress fractures in a collegiate football player. Clin J Sport Med 1999; 9:95-97.

-6 Lehman TP, Belanger MJ, Pascale MS: Bilateral proximal third fibular stress fractures in an adolescent female track athlete. Orthopedics 2002;25:329-332.

7 Peiro V, Herrador MA, Leyes M, Guillen P: Bilateral stress fracture of the proximal fibula in a young soccer player on bone scanning. Clin Nucl Med 2003;28:49-51.

$\checkmark 8$ Roth S, Sestan B, Tudor A, Dapic T, Cicvaric T, Miletic D: Bilateral fibular stress fracture in a young female basketball player. J Pediatr Orthop B 2008;17:195-198.
9 Lord CD, Coutts JW: A study of typical parachute injuries occurring in two hundred and fifty thousand jumps at the parachute school. J Bone Joint Surg 1944;26:547-557.

10 Sawant MR, Bendall SP, Kavanagh TG, Citron ND: Nonunion of distal stress fractures in patients with deformed arthritic knees. Treatment using modular total knee arthroplasty. J Bone Joint Surg 2000;82:663-666.

11 Lambert KL: The weight-bearing function of the fibula. A strain gauge study. J Bone Joint Surg 1971;53:507-513.

12 Takebe K, Nakagawa A, Minami H, Kanazawa $\mathrm{H}$, Hirohata $\mathrm{K}$ : Role of the fibula in weight-bearing. Clin Orthop Relat Res 1984; 184:289-292. 